\title{
DIAGNÓSTICO DAS PRÁTICAS PEDAGÓGICAS ANTIRRACISTAS INCLUSIVAS NOS CONTEXTOS ESCOLARES DA EDUCAÇÃO BÁSICA DA REGIÃO DO SERIDÓ/RN
}

\author{
DIAGNOSIS OF ANTI-RACIST PEDAGOGICAL PRACTICES INCLUDING IN SCHOOL CONTEXTS OF BASIC \\ EDUCATION IN THE SERIDÓ/RN REGION
}

\section{DIAGNÓSTICO DE PRÁCTICAS PEDAGÓGICAS ANTIRACISTAS INCLUYENDO EN CONTEXTOS ESCOLARES DE EDUCACIÓN BÁSICA EN LA REGIÓN SERIDÓ / RN}

\author{
Jacicleide Ferreira Targino da Cruz Melo ${ }^{1}$ \\ Débora Costa ${ }^{2}$
}

1. Doutora e mestra em Educação. Professora adjunta da Universidade Federal do Rio Grande do Norte. E-mail: jacicleide.melo@ufrn.br

2. Graduanda em Pedagogia e bolsista de iniciação científica. Universidade Federal do Rio Grande do Norte. E-mail: debora.costa.016@ufrn.edu.br

\begin{abstract}
RESUMO: Este artigo apresenta resultados de uma pesquisa vinculada a um Projeto de Pesquisa aprovado pelo PPG/PROPESQ Edital $\mathrm{N}^{\circ}$ 01/2019 - Apoio a grupos Emergentes para Criação de Programas de Pós-Graduação. O objetivo foi realizar um diagnóstico das práticas pedagógicas antirracistas inclusivas nos contextos escolares da educação básica da região do Seridó/RN. Trata-se de uma pesquisa de abordagem qualitativa do tipo exploratória, contou com a participação de dezesseis escolas de distintas cidades do Seridó/RN que responderam dois questionários online. Um dos questionários foi destinado para os coordenadores das instituições de ensino, onde obteve-se resposta de cinquenta docentes. Além da análise das respostas dos questionários, as discussões desse texto se ancoram na Lei 10.639/2003 e o Plano Nacional de Implementação das Diretrizes Curriculares Nacionais para a Educação das Relações Étnico-Raciais e para o Ensino de História e Cultura Afro-Brasileira e Africana (BRASIL, 2009). Os resultados indicam a ausência de estudos específicos que favoreçam a inclusão de práticas pedagógicas antirracista no contexto investigado; por conseguinte, apresentam a necessidade da oferta de cursos de Pós Graduação que ofereça informações/conhecimentos para um melhor entendimento do racismo, da História da África, Culturas AfroBrasileiras e das trajetórias dos movimentos sociais negros.
\end{abstract}

Palavras-chave: Inclusão. Diversidade Práticas Pedagógicas. Antirracista.

\begin{abstract}
This article presents the results of a research linked to a Research Project approved by the PPG/PROPESQ Notice No. 01/2019 - Support to Emerging Groups for the Creation of Graduate Programs. The objective was to carry out a diagnosis of inclusive anti-racist pedagogical practices in school contexts of basic education in the region of Seridó/RN. This is a qualitative exploratory research, with the participation of sixteen schools from different cities in Seridó/RN that answered two online questionnaires. One of the questionnaires was sent to the coordinators of educational institutions, where a response was obtained from fifty professors. In addition to analyzing the responses to the questionnaires, the discussions in this text are based on Law $10.639 / 2003$ and the National Plan for the Implementation of the National Curriculum Guidelines for the Education of EthnicRacial Relations and for the Teaching of Afro-Brazilian and African History and Culture (BRAZIL, 2009). The results indicate the absence of specific studies that favor the inclusion of anti-racist pedagogical practices in the investigated context; therefore, they present the need to offer postgraduate courses that offer information/knowledge for a better understanding of racism, the History of Africa, Afro-Brazilian Cultures and the trajectories of black social movements.
\end{abstract}

Key words: Inclusion. Diversity. Pedagogical practices. Anti-racist.
RESUMEN: Este artículo presenta los resultados de una investigación vinculada a un Proyecto de Investigación aprobado por el Aviso PPG / PROPESQ No. 01/2019 Apoyo a Grupos Emergentes para la Creación de Programas de Posgrado. El objetivo fue realizar un diagnóstico de prácticas pedagógicas antirracistas inclusivas en contextos escolares de educación básica en la región de Seridó / RN. Se trata de una investigación exploratoria cualitativa, con la participación de dieciséis escuelas de diferentes ciudades de Seridó / RN que respondieron dos cuestionarios online. Uno de los cuestionarios fue enviado a los coordinadores de instituciones educativas, donde se obtuvo respuesta de cincuenta profesores. Además de analizar las respuestas a los cuestionarios, las discusiones en este texto se basan en la Ley 10.639 / 2003 y el Plan Nacional para la Implementación de los Lineamientos Curriculares Nacionales para la Educación de las Relaciones Étnico-Raciales y para la Enseñanza de los Afrobrasileños. e Historia y Cultura Africanas (BRASIL, 2009). Los resultados indican la ausencia de estudios específicos que favorezcan la inclusión de prácticas pedagógicas antirracistas en el contexto investigado; por tanto, presentan la necesidad de ofrecer cursos de posgrado que ofrezcan información / conocimiento para una mejor comprensión del racismo, la Historia de África, las Culturas Afrobrasileñas y las trayectorias de los movimientos sociales negros.

Palabras-clave: Inclusión. Diversidad. Prácticas pedagógicas. Antiracista.

Recebido em: 11/06/2021

Aprovado em: 14/11/2021 
Todo o conteúdo deste periódico está licenciado com uma licença Creative Commons (CC BY-NC-ND 4.0 Internacional), exceto onde está indicado o contrário.

\section{Introdução}

Durante muito tempo a cultura escolar se configurou a partir da ênfase em práticas que se refletiam na afirmação da hegemonia da cultura ocidental europeia e a ausência no currículo e em outras práticas simbólicas presentes na escola de outras culturas, particularmente as originárias do nosso continente, à cultura negra e de outros grupos marginalizados de nossa sociedade.

Todavia, a partir dos levantes dos movimentos negros e que encontraram espaço na agenda política ao menos dos últimos anos (2003-2008), onde governantes estiveram mais sensíveis as suas demandas permitindo oficialmente abertura para, na escola, diminuir o abismo construído entre a cultura hegemônica europeia em detrimento da diversidade racial brasileira. Apesar da LDB, no art. $3^{\circ}$ reiterar os princípios de igualdade estabelecidos na Constituição Federal (BRASIL, 1988) para a Educação, e inserir outros. Somente com a Lei n ${ }^{\circ} 10.639 / 2003$ - que em seu principal artigo 26-A - ancora a educação antirracista na legislação educacional e depois suplantado pela Lei 11.645/2008, a qual define que o currículo da Educação Básica deve ter conteúdo das culturas africana, afro-brasileira e indígena. Com isso, legalmente, hoje existem diretrizes educacionais, que orientam a inclusão dessas temáticas no currículo escolar e, principalmente, disseminação de práticas antirracistas no âmbito educacional.

Apresentamos, neste artigo, os resultados de uma pesquisa exploratória, com abordagem qualitativa, que objetivou realizar mapeamento de práticas pedagógicas antirracistas inclusivas nos contextos escolares da educação básica da região do Seridó /RN, possuindo como principal meta, a partir dos achados da investigação, auxiliar na construção de um Programa de Pós-Graduação na área de Ensino, constituído por professores do Departamento de Educação, do Centro de Ensino Superior do Seridó pertencente a Universidade Federal do Rio Grande do Norte - UFRN, localizado no município de Caicó/RN.

O Projeto que deu origem a Pesquisa foi aprovado pelo PPG/PROPESQ Edital No 01/2019 - Apoio a grupos Emergentes para Criação de Programas de Pós-Graduação possuindo três bolsistas remuneradas e uma voluntária, com temáticas de investigação que se interligam diretamente com a questão da inclusão de alunos no cotidiano escolar, seja ele por ser uma criança com deficiência ou por ser negro.

Neste sentido, o trabalho em tela, objetiva analisar as iniciativas desenvolvidas pelas redes públicas de ensino com relação a práticas pedagógicas voltadas para a Educação das Relações Étnico-Raciais em escolas pertencentes a região do Seridó/RN.

Para isso, se ancora em documentos legais que amparam a inclusão da temática antirracista no contexto da Educação Básica, tais como: a Constituição Federal (BRASIL, 1988), as leis 11.645/2008 que altera a Lei 9.394/1996, modificada pela Lei 10.639/2003, o Plano Nacional de Implementação das Diretrizes Curriculares Nacionais para a Educação das Relações Étnico-Raciais e para o Ensino de História e Cultura Afro-Brasileira e Africana.

Além disso, para a realização do mapeamento de práticas pedagógicas antirracistas inclusivas nos contextos escolares da educação básica da região do Seridó/RN, foi elaborado e aplicado um questionário com docentes e coordenadores das instituições escolares selecionadas para fazer parte da pesquisa. As informações obtidas a partir da construção dos dados evidenciam qual o espaço que a temática antirracista ocupa nas ações educativas do contexto investigado. 
Considerando, a perspectiva interpretativa de análises de dados, nesse artigo, promovemos um diálogo entre os dados construídos a partir da investigação empírica e os documentos oficiais que orientam as práticas pedagógicas no que se referem às relações étnico-raciais, dando visibilidade a essa temática que historicamente é negada no âmbito escolar, através dos conteúdos curriculares, da prática pedagógica, dentre outros mecanismos.

\section{Metodologia}

A pesquisa foi realizada a partir de um estudo descritivo e exploratório, com uma abordagem qualitativa. Lakatos e Marconi (2009) mostram que a utilização de uma análise qualitativa é mais complexa e detalhada, tendo em vista que trabalha com investigações dos hábitos, atitudes e tendências do comportamento humano.

De acordo com Lüdke e André (1986) a abordagem qualitativa promove o confronto entre os dados, as evidências, as informações construídas sobre determinado assunto e o conhecimento teórico acumulado a respeito dele. Selltiz et al. (1965) diz que, enquadra-se na categoria dos estudos exploratórios todos aqueles que buscam descobrir ideias e intuições, na tentativa de adquirir maior familiaridade com o fenômeno pesquisado. Selltiz et al. (1965) ainda evidencia que este tipo de pesquisa busca descrever um fenômeno ou situação em detalhe, especialmente, o que está ocorrendo, permitindo abranger, com exatidão, as características de um indivíduo, uma situação, ou um grupo, bem como desvendar a relação entre os eventos.

Para Triviños (1987, p. 110), "o estudo descritivo pretende descrever os fatos e fenômenos de determinada realidade", de modo que o estudo descritivo é utilizado quando a intenção do pesquisador é conhecer determinada comunidade, suas características, valores e problemas relacionados à cultura. Segundo o autor, o uso da descrição qualitativa procura captar não só a aparência do fenômeno como também suas essências, procurando explicar sua origem, relações e mudanças, e tentando intuir as consequências.

A partir dessa conceituação, o plano de pesquisa que deu origem a esse estudo ocorreu a partir do seguinte processo de pesquisa: primeiramente, foi feita uma revisão bibliográfica, para analisar como a questão étnico-racial veio sendo concebida historicamente e quais reflexões são feitas atualmente sobre ela. Além de um levantamento dos documentos promulgados a partir de 2003, ou seja, posteriores as Leis 10.639/03 e 11.645/2008 - procurando identificar o que as leis, políticas públicas, regulamentações e políticas internacionais, nacionais e municipais dizem a respeito da diversidade étnico-racial e sua influência nas políticas educacionais brasileiras.

Na segunda etapa da investigação foi realizada uma pesquisa de campo - a partir de um questionário que foi aplicado aos professores das escolas pesquisadas, com vistas a diagnosticar as práticas pedagógicas antirracistas inclusivas nos contextos escolares da educação básica da região do Seridó/RN.

Apesar da pandemia não possibilitar essas visitas aos municípios, foi feito um contato com as escolas escolhidas, sendo o mesmo por e-mails, telefonemas e pelo aplicativo WhatsApp apresentando os objetivos e metodologia da pesquisa. Das vinte e cinco escolas escolhidas dezesseis aceitaram participar, três escolas por distintos motivos decidiram não participar, cinco não retornou o questionário com as respostas e uma não conseguimos estabelecer contato.

Após os contatos estabelecidos, foram elaborados os questionários eletrônicos, sendo dois: um para os docentes e o outro para a coordenação e/ou direção das escolas pesquisadas. O questionário elaborado 
para os professores contou com quarenta e nove perguntas e o que foi destinado aos coordenadores e/ou direção seis perguntas.

Por meio dos procedimentos supracitados, os dados da pesquisa foram analisados minuciosamente, a partir da perspectiva interpretativa, considerando os elementos inerentes aos eventos sociais, instituições, processos, diferentes formas de interpretações/significados variados atribuídos pelos participantes às suas experiências e vivências (GEERTZ, 2008). Para isso, os professores pesquisadores e os bolsistas envolvidos na pesquisa se reuniram sistematicamente, objetivando subsidiar o processo da investigação, no tocante a minimizar as dificuldades no processo de construção e análises dos dados, como também, na elaboração do relatório de pesquisa.

Gil (1995, p. 128) mostra que este método é viável para pesquisa de cunho qualitativo, principalmente em pesquisas de grande escala porque atinge grande número de pessoas, mesmo que estejam distribuídas geograficamente, além disso, é uma das técnicas de investigação que tem por objetivo o conhecimento de opiniões, crenças, sentimentos, interesses, expectativas, situações vivenciadas, etc; além de não expor os pesquisadores à influência das opiniões e de aspectos pessoais do entrevistado.

As respostas, assim como as leituras nos documentos e demais materiais bibliográficos selecionados compuseram as informações que serão tratadas e apresentadas por meio das interpretações/análises e argumentações que seguem nos resultados e discussão.

\section{Resultados e discussão}

Apresentamos, nesse tópico, uma análise dos elementos teóricos em diálogo com os dados empíricos construídos no decorrer do desenvolvimento do plano de pesquisa realizada, a fim de dá validade ao diagnóstico sobre Práticas Pedagógicas Antirracistas Inclusivas nos Contextos Escolares da Educação Básica da Região do Seridó/RN.

\section{ANÁLISE DAS POLÍTICAS AFIRMATIVAS ANTIRRACISTAS INCLUSIVAS PARA OS CONTEXTOS ESCOLARES DA EDUCAÇÃO BÁSICA}

De acordo com o Art. 205 da Constituição Federal de 1988, "a educação é um direito de todos [...]" (BRASIL, 1998, s/p). Logo, como uma política pública de caráter universal, a educação passa a ser um direito constitucional e subjetivo, em outras palavras, a educação básica e de qualidade passa a ser para todos, sem quaisquer distinções.

A Lei 9.394/1996, por sua vez, seguindo essa mesma prerrogativa da Constituição Federal (1988), em seu art. 26 estabelece que os currículos da Educação Infantil, do Ensino Fundamental e do Ensino Médio devem contemplar "uma parte diversificada, exigida pelas características regionais e locais da sociedade, da cultura, da economia e dos educandos" (BRASIL, 1996, s/p).

Ainda, na década de 1990, foi publicado os Parâmetros Curriculares Nacionais (BRASIL, 1997) que em um dos seus módulos contemplou o tema transversal Pluralidade Cultural com ênfase em questões da diversidade em uma perspectiva universalista de educação e de política educacional.

Contudo, o caráter genérico com relação às questões de diversidade, é revisto e alterado quando ocorre a sanção da Lei 10.639/03, pela qual o trabalho dos operadores pedagógicos adquiriu as tarefas de se empenhar na superação de um sistema escolar racista reprodutor das desigualdades raciais e sociais e na superação de um sistema educacional marcado, numa perspectiva histórica de longa duração, por um 
processo educativo formalizado no embranquecimento cultural/social e desqualificador do continente africano e dos negros. A referida normativa institui a obrigatoriedade do ensino de história da África e das culturas Afro-brasileiras nas escolas públicas e particulares do ensino fundamental e médio, ou seja, da escolarização básica:

Art. 26-A. Nos estabelecimentos de ensino fundamental e médio, oficiais e particulares, torna-se obrigatório o ensino sobre História e Cultura Afro-Brasileira .

$\S 1^{\circ} \mathrm{O}$ conteúdo programático a que se refere o caput deste artigo incluirá o estudo da História da África e dos Africanos, a luta dos negros no Brasil, a cultura negra brasileira e o negro na formação da sociedade nacional, resgatando a contribuição do povo negro nas áreas social, econômica e política pertinentes à História do Brasil.

$\S 2^{\circ}$ Os conteúdos referentes à História e Cultura Afro-Brasileira serão ministrados no âmbito de todo o currículo escolar, em especial nas áreas de Educação Artística e de Literatura e História Brasileiras.

Art. 79-B. O calendário escolar incluirá o dia 20 de novembro como 'Dia Nacional da Consciência Negra (BRASIL, 2003, s/p).

Essa lei passa a se constituir como uma política afirmativa de valorização e respeito aos processos históricos da identidade e cultura do povo negro no Brasil. Todavia, em 2008 essa lei vai ser alterada pela Lei 11.645/08 para incluir a temática indígena. Esse amparo legal tornou-se, dentro da concepção de ensino inclusiva, um instrumento de combate ao preconceito racial e a influência do viés eurocentrista (única possibilidade de produzir cultura e interpretar o mundo - reduz a história milenar da civilização africana à captura e escravização dos negros e, a do índio a uma visão superficial de quem ele, de modo estereotipado, como uma figura fictícia criada em romances ou "lembrado" somente em uma pintura no rosto das crianças no dia 19 de abril.).

Desse modo, essas leis consubstanciam no reconhecimento e valorização das matrizes africanas indígenas da cultura brasileira, juntamente com a indígena, europeia e asiática, bem como na reparação histórica diante das atrocidades ocorridas na construção do país e na necessidade de revisão da historiografia do Brasil.

Assim, as referidas leis vão subsidiar o Plano Nacional de Implementação das Diretrizes Curriculares Nacionais para a Educação das Relações Étnico-Raciais e para o Ensino de História e Cultura Afro-Brasileira e Africana que tem como perspectiva agregar elementos da cultura afro-brasileira; além disso, flexibilizar os currículos oficiais para que os mesmos possam contemplar conteúdos pertinentes às necessidades do local em que atuam e estejam em consonância com a eliminação do racismo e dos preconceitos.

Em que pese esse Plano é constituído por seis eixos fundamentais. O primeiro é sobre o fortalecimento do marco legal, em outras palavras, seria a urgência na regulamentação das Leis supracitadas no âmbito dos municípios, estados e Distrito Federal, assim como a inclusão do Plano Nacional de Educação (PNE). O segundo e terceiro eixo, representam respectivamente, sobre a política de formação para gestores(as) e profissionais da educação e, sobre a política de material didático e paradidático sobre a questão ético-racial.

O quarto eixo, por sua vez, refere-se a gestão democrática e mecanismos de participação social cogita a necessidade do fortalecimento de processos, instâncias e mecanismos de controle e participação social, tendo em vistas implantar as Leis $n^{\circ} 10.693 / 03$ e 11.645/08. O quinto eixo, aborda avaliações e monitoramentos, apontando para construções de indicadores que permitem monitorar a implementação da 
Lei $\mathrm{n}^{\circ} 10.639 / 03$, isso com a cooperação dos Municípios, Estados e a União, promovendo o aprimoramento de políticas públicas que enfrentem a desigualdade racial na educação.

O sexto e último eixo, indica possibilidades orçamentárias necessárias para a implementação da lei. Além disso, reafirma a necessidade de as secretarias estaduais e municipais de educação incluir nos seus contextos as temáticas étnico-raciais e diversidade.

De maneira geral, o Plano destaca as atribuições do sistema de ensino, como também das instituições de ensino (sendo elas da rede pública ou particular), que resumidamente, possuem a obrigação de reformular o Projeto Político Pedagógico junto à comunidade escolar, com o objetivo de garantir a existência da temática das relações étnico-raciais no planejamento dos professores; detectar e combater com medidas socioeducativas casos de racimo, preconceito e discriminação no ambiente escolar.

Segundo o Plano, as ações centrais da Educação Infantil e do Ensino Fundamental é a ampliação do acesso de crianças afrodescendentes, assegurar formações específicas na área, valorização da diversidade étnica, religiosa, de gênero e de pessoas com deficiências, a busca pela aquisição de livros que possuam histórias de indígenas, negros e culturas afins, pesquisas, desenvolvimento e aquisição de materiais didático-pedagógicos que respeitem e promovam a diversidade, incentivar a participação de pais e responsáveis pela criança no planejamento do projeto político-pedagógico, abordar a temática étnico-racial durante todo o ano letivo e apoiar ações que contribua para a formação e fortalecimento da autoestima dos jovens.

O Plano direciona, ainda, ações relacionadas à Educação de Jovens e Adultos (EJA) no tocante ao aumento do número de afrodescendentes matriculados nesse segmento de ensino, a inclusão do quesito cor/raça nos diagnósticos e programas, ações de pesquisa, desenvolvimento e aquisição de materiais didático-pedagógicos que respeitem, valorizem, promovam a diversidade e incluir na formação de educadores de EJA a temática da promoção de igualdade étnico-racial e o combate ao racismo. Visto que, segundo dados do censo do IBGE/2010 a taxa de analfabetismo absoluta acima de 15 anos é de 16,9\% para negros e $7,1 \%$ para brancos. $\mathrm{O}$ analfabetismo funcional por sua vez apresenta $32,3 \%$ para população negra e 18,4\% para a população branca, o número da população negra é ascendente a da branca, e um dos motivos é o mercado de trabalho informal que os afastam do ensino regular.

Por fim, o Plano dá ênfase a educação escolar quilombola, estabelecendo como umas das ações fundamentais aumentar a oferta de ensino nas comunidades quilombolas garantindo o direito à educação básica para a comunidade, promover formação continuada de professores(as) da educação básica que atuam em comunidade quilombolas, capacitação de gestores(as) locais, editar e distribuir materiais didáticos.

Ante o exposto, podemos observar que como desdobramento das Leis e documentos oficiais delineados, o processo de construção de uma educação comprometida com a diversidade e com o combate ao racismo e diferentes formas de discriminação, tem ganhado espaço no âmbito das políticas educacionais no Brasil. Neste sentido, coloca-se ao sistema educacional brasileiro a obrigatoriedade de desenvolver uma educação antirracista que, contribuindo para a valorização positiva da identidade negra, favoreça a superação nos espaços escolares das práticas de preconceito e de discriminação raciais. Por outro lado, a promoção de uma educação antirracista exige da parte dos professores o compromisso individual/profissional de compreensão dessa estrutura racista numa perspectiva histórica, social e antropológica para rompimento com a cultura eurocêntrica que, ao longo dos séculos, tem sido disseminada no âmbito escolar e, criar espaços que proporcionem a reflexão crítica sobre os mecanismos de exclusão, a fim de que, os discentes compreendam sua própria história e construam positivamente sua identidade cultural. 
Todavia, com base nessas ponderações, o diagnóstico feito por meio da pesquisa efetivada na região do Seridó/RN pode nos dá pistas se as práticas antirracistas ainda ocupam um lugar periférico nas práticas de ensino em alguns contextos de ensino.

\section{DIAGNÓSTICO DOS DESAFIOS E POSSIBILIDADES PARA PRÁTICAS PEDAGÓGICAS ANTIRRACISTAS INCLUSIVAS NOS CONTEXTOS ESCOLARES DA EDUCAÇÃO BÁSICA DA REGIÃO DO SERIDÓ/RN}

Em linhas gerais, a pesquisa de campo revelou pontos importantes para a reflexão sobre os desafios e possibilidades para práticas pedagógicas antirracistas inclusivas nos contextos escolares da Educação Básica da Região do Seridó/RN.

Destacaremos algumas das principais reflexões advindas da pesquisa empírica onde houve aproximação com vinte e quatro escolas da região do Seridó situada no RN, mas conseguimos estabelecer contato continuo para obtenção de informações sobre a inclusão da temática antirracista nas práticas pedagógicas desenvolvidas com dezesseis escolas (que prontamente deu retorno aos questionários de pesquisa).

De acordo com as respostas dos dois questionários (um aplicado com Coordenadores Pedagógicos e outro com Professores), constatamos que a temática antirracista não é invisível, ou seja, os coordenadores e os docentes das instituições são conscientes de sua existência, apesar de ser um conhecimento superficial, visto que, segundo dados dos questionários aplicados, eles não têm estudos na área (tanto no que diz respeito a legislação que ampara a temática quanto ao referencial bibliográfico na área).

De maneira geral, a investigação revelou que apesar da questão étnica racial não ser desconhecida para os Coordenares e Professores pesquisados, eles possuem pouco conhecimento sobre essa temática. Dos quatro coordenadores, apenas dois possuem leituras sobre alguns documentos curriculares. No entanto, assumem que não tem aprofundamento na área e, ainda necessitam de mais apropriações sobre as temáticas inclusão, diversidade, antirracismo.

Concordamos com Corenza (2018) quando ressalta que, a formação profissional pode ser um espaço que proporciona debates, construção de conhecimento e apreciação de um saber. Compreendemos que, a educação antirracista na formação continuada é uma forma de expandir a prática pedagógica e os conteúdos disciplinares aos professores(as) que não tiveram uma experiência com a educação das relações étnicoraciais na sua formação inicial. Essa formação associada a uma formação cultural e humanista que lhes permita compreender e problematizar a realidade social e seu trabalho, ou seja, formando-se e, continuamente, empoderando-se para que sejam sujeitos e lideranças neste processo em busca de uma educação antirracista.

Segundo Tardif (2008), a atividade docente é realizada em uma rede de interações com outros sujeitos mediados por discursos, comportamentos, maneiras de ser que vão sendo incorporadas a sua prática. Saberes que devem estar " [...] em íntima relação com o que os professores, nos espaços de trabalho cotidiano, são, fazem, pensam e dizem” (p. 18). Dessa forma, torna-se imprescindível considerar a diversidade de aspectos que permeiam a formação e a prática docente frente aos processos de construção do conhecimento que caminhe na contramão de uma formação reprodutora e excludente.

Tratando-se da análise aos questionários aplicados com os docentes participantes da pesquisa, observamos uma situação mais complexa, visto que, ao analisar as respostas dos pesquisados identificamos que há brechas formativas no que concerne aos estudos sobre inclusão e, por conseguinte aos estudos na 
área da educação étnico-racial - apenas 47,9\% dos docentes entrevistados possuem conhecimento de autores ou documentos oficiais que trabalha o tema em questão. Além disso, demonstram insegurança para desenvolver práticas de ensino nessa perspectiva - como expressa o gráfico abaixo:

Figura 1 - Percepção dos professores acerca da sua qualificação para lecionar no contexto de diversidade e inclusão.

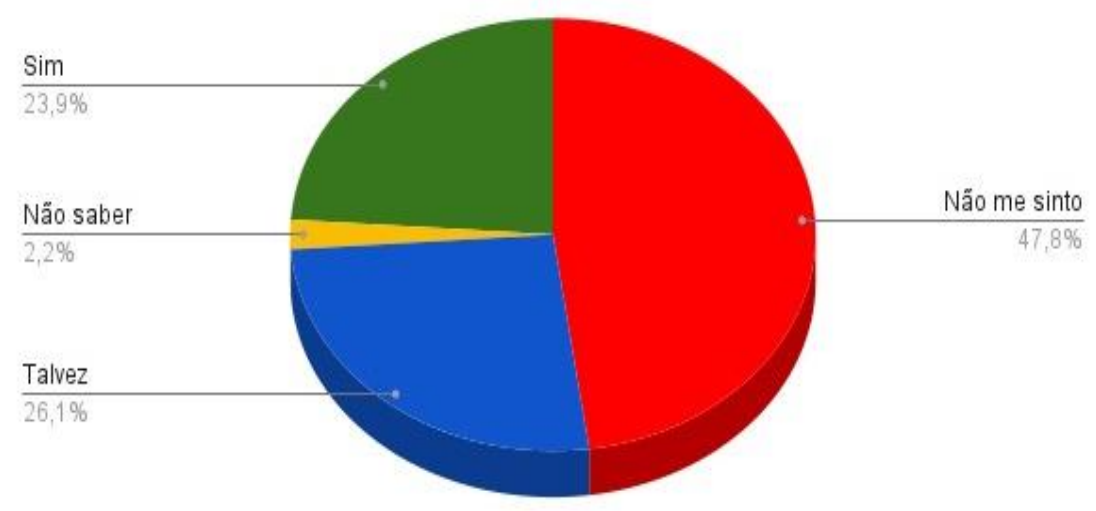

Fonte: Elaborado pelas autoras (2020).

Quando perguntados sobre se sentirem qualificados para lecionar no contexto de diversidade e inclusão, 47,8\% disseram que não se sentem qualificados; 26,1\% responderam que talvez; 2,2\% destacaram não saber e apenas $23,9 \%$ afirmaram se sentir qualificado para lecionar em contexto de diversidade e inclusão. Inferimos que isso se dá porque quando perguntados sobre ter feito algum curso na área - 50\% (metade dos pesquisados) disseram não possuir nenhuma formação na área. Decorrente dessas respostas, interpretamos que o trabalho pedagógico envolvendo a Educação das Relações Étnico-Raciais - ainda é superficial porque há pouco conhecimento conceitual sobre a África e sua inter-relação com as questões afro-brasileiras.

Neste sentido, a falta de uma formação especializada nessa área acaba se constituindo como um limite e um desafio, visto que, acaba desconsiderando as diferenças étnicas e de pertencimento regional. Todavia, quando perguntados sobre a viabilidade de uma pós-graduação na área da diversidade e inclusão - 89,1\% apontaram como uma possibilidade para uma aproximação maior com discussão da diversidade comprometida com um projeto social, político e ético antirracista. Já que $63 \%$ dos professores pesquisados dizem que não encontram a oferta de cursos de formação na área da diversidade que incluam os estudos étnico-raciais, ou seja, mesmo com o interesse em buscar por cursos que tratem dessa temática, na região do Seridó/RN, atualmente, há dificuldades para encontrá-los.

Pontuamos, portanto, que investir na formação dos docentes por meio de cursos de formação continuada é uma possibilidade para se desvencilhar de práticas pedagógicas monocultural que impõem aos discentes uma história e padrões que não são totalmente seus.

Outra possibilidade está relacionada às Secretarias de Educação dar subsídios para que os docentes da escola pública, que atendem a grande maioria dos negros e pardos, tenham condições de rever suas práticas pedagógicas. 
Consideramos, ainda, que é de extrema necessidade o conhecimento dos marcos legal (BNCC, Leis $\mathrm{n}^{\circ} 10.693 / 03$ e 11.645/08), tendo em vista que poderá favorecer a construção de práticas pedagógicas que incluam estudos e atividades relacionadas com a diversidade étnico-racial. E, como nos diz Santos (2006, p. 326), além de outras tantas coisas, "temos direito à igualdade quando a diferença nos inferioriza, temos direito à diferença quando a igualdade nos descaracteriza". Isso significa que precisamos desaprender o preconceito e aprender a pluralidade, abdicando de uma homogeneização entre os "diferentes".

Os dados delineados, sobre a pesquisa realizada, demonstram que trabalhar com a temática do antirracismo na sala de aula, implica em uma série de questões que vão muito além do currículo ou da legislação em si, principalmente, em relação aos docentes e a sua formação inicial, as suas concepções de ensino e até as suas relações com o tema. Exige, ainda, pensar no espaço escolar como um local de diferentes sujeitos, como território atravessado pela diversidade cultural, é pensar no trabalho em que o professor exercerá enquanto mediador das relações de ensino-aprendizagem, relações éticas e conflitos de ideologias. Segundo Oliveira, que aborda especificamente o ensino da História da África:

[...] exigir dos docentes a aplicação das novas diretrizes que incluem nos currículos, histórias da África e das relações étnico-raciais em educação, significa mobilizar subjetividades, desconstruir noções e concepções apreendidas durante os anos de formação inicial e enfrentar preconceitos raciais muito além dos muros escolares (OLIVEIRA, 2007, p. 01).

Isto posto, o estudo apontou que, além da falta de uma formação inicial que contemple mais profundamente a temática da diversidade, um dos fatores que contribuem para a não disseminação de práticas de ensino antirracistas nas escolas da região do Seridó/RN, também, envolve: a formação de pessoas em valores, atitudes, relações construtivas, colaborativas, ou seja, a formação como pessoas que partilham responsabilidades, uma formação que lhes permita exercer a cidadania com a consciência clara de direitos e deveres, dos cuidados de si e do outro. Além disso, eliminar atitudes preconceituosas, estigmatizantes, estereotipadas e discriminatórias.

Para isso, compreendemos a necessidade de os professores desconstruir saberes científicos e históricos, construir novas leituras e interpretações no campo do conhecimento histórico por meio formações continuadas sobre a temática étnico-racial, construam reflexões acerca da colonialidade do poder, do saber e do ser e também as possibilidades de novas construções teóricas baseadas em uma proposta de interculturalidade crítica e uma pedagogia decolonial.

Importante salientar que, neste trabalho, entende-se que os modos de subjetivação oferecem certa regulação no processo de estruturação de um sujeito. Nesse sentido, a subjetividade manifesta-se, revelase, converte-se, materializa-se e objetiva-se no sujeito a partir não somente dos aspectos cognitivos, mas também, históricos e culturais. Segundo Vygotsky (1991) a constituição do sujeito ocorre na e pela interação humana, todavia, enfatizou que essa interação acontece em situações concretas de vida, na prática humana que atribui significado à produção material e à produção cultural, obras do humano, e não por meio de abstracionismos isolados ou reflexos reagentes.

Nos cadernos de orientação curricular do MEC, denominados Indagações sobre o Currículo, no volume Diversidade e Currículo. Nilma Lino Gomes diz que falar sobre diversidade e diferença implica posicionar-se contra processos de colonização e dominação. "É perceber como, nesses contextos, algumas diferenças foram naturalizadas e inferiorizadas sendo, portanto, tratadas de forma desigual e 
discriminatória. É entender o impacto subjetivo destes processos na vida dos sujeitos sociais e no cotidiano da escola" (BRASIL, 2007, p. 25).

No campo do conhecimento social e histórico, é possível afirmar que existe a negação de histórias, saberes de indivíduos com culturas e organizações políticas e sociais oriundas do continente africano. De acordo com a pesquisa realizada no Seridó/RN, observa-se que ainda se perpetua uma interpretação histórica hegemônica do eurocentrismo, sobretudo, porque os professores não foram formados para analisarem a questão étnico-racial em relação ao eurocentrismo. Nota-se que mesmo com o advento das Leis $n^{\circ} 10.639 / 03$ e $n^{\circ} 11.645 / 08$ destaca-se que muitos professores não são preparados para aplicar conceitos de estudos históricos de nossas etnias e de onde vem nossa origem, fundamentando-se em análises documentais (museus, bibliotecas entre outros) relacionando às raízes étnicas ao qual derivamos.

Assim, a análise dos resultados, aponta a necessidade de uma formação docente específica para lidar em contextos de diversidade. Perante tal afirmativa, reforça a ideia de criar um Programa de Pós- Graduação na região do Seridó do Rio Grande do Norte que contemple "Ensino e Diversidade" na construção de uma pedagogia antirracista e inclusiva, contribuindo, então, para estudos, debates, na instrumentalização das Lei 10.639/03 e 11.645/08, que possibilita desmistificar e desconstruir de maneira contra hegemônica as produções discursivas eurocêntricas e desenvolvimento práticas antirracistas e inclusivas em sala de aula.

\section{Considerações finais}

O objetivo deste artigo foi apresentar resultados de um mapeamento realizado para analisar as iniciativas desenvolvidas pelas redes públicas de ensino com relação a práticas pedagógicas voltadas para a Educação das Relações Étnico-Raciais em escolas pertencentes a região do Seridó/RN. Neste sentido, o trajeto trilhado na pesquisa possibilitou conhecer as limitações/desafios e as possibilidades para que ocorram práticas pedagógicas antirracistas inclusivas nos contextos escolares da Educação Básica da região do Seridó/RN.

A análise dos dados apresentados indica vestígios de que a inclusão de práticas pedagógicas antirracista ainda não é efetiva. Apesar de ter conhecimento sobre a importância da temática, os docentes demonstram pouco conhecimento sobre a área e admite, em sua maioria, não ter qualificação para o trabalho nessa perspectiva. Por conseguinte, sinalizam que essa pouca aproximação com o trabalho étnico-racial na sala de aula pode ser sanada com cursos de formação que dê ênfase às questões da diversidade étnico-racial e inclusão.

Por outro lado, a partir das leituras realizadas, foi possível inferir que o desafio para a inclusão de práticas pedagógica antirracista vai muito além de incluir no currículo oficial da escola a obrigatoriedade da temática história e cultura afro-brasileira e indígena. O principal objetivo da luta pela inclusão é diagnosticar as necessidades do contexto em que cada escola está inserida. O Brasil é um país riquíssimo em miscigenação. Segundo o IBGE ele é formado por negros, brancos, indígenas, pardos e amarelos. Ainda assim é nítido o monopólio que sofremos da cultura europeia - tanto na educação como na cultura em geral. Por conseguinte, a representação dos povos africanos e também indígenas é feita erroneamente nos nossos livros de história, além disso, nos planejamentos pedagógicos anuais não há preocupação na inclusão de discussões sobre preconceito e racismo.

No tocante a região do Seridó/RN, diante dos dados construídos por meio da pesquisa, identificou a necessidade de ampliar o repertório/conhecimento dos docentes sobre a diversidade, visto que, ainda existe um abismo entre as teorias/produções escritas, a legislação na área, realidade de pessoas negras e a 
escola. Apesar de existir documentos oficiais que orientam a inclusão da educação antirracista, infelizmente, no contexto da prática de ensino está longe dela se evidenciar.

Diante dessa realidade, na região do Seridó/RN, consideramos viável a criação de uma Pós Graduação nessa área, oferecida por meio do Centro de Ensino Superior do Seridó/CERES - pertencente a Universidade Federal do Rio Grande do Norte/UFRN (que é o principal centro de referência de formação em nível superior do Seridó/RN), visto que, possui cursos de licenciatura, inclusive a graduação em Pedagogia oferece componentes curriculares na área da inclusão e diversidade étnico-racial, além disso, há linhas de pesquisa na área e, isso denota que há profissionais qualificados.

Assim, podemos extrair de um Programa de Pós Graduação na área da inclusão e diversidade aprendizados que torne os docentes aptos a perceber as hierarquias raciais de seu contexto e, principalmente, desnaturalizar de suas práticas de ensino o que o racismo naturalizou. Neste sentido, procura-se nesse texto o apoio teórico indispensável para o debate sobre a diversidade, sobretudo, os desdobramentos para o processo educativo no que concerne à etnia, diferença, desigualdades. E para tanto, foi necessário, delinear com base na pesquisa, as limitações que dificultam o desenvolvimento de um currículo e práticas de ensino que desconstruam a questão eurocêntrica e monocultural no âmbito escolar, intimamente ligada com viés ideológico do eurocentrismo - paradigma que durante muito tempo - invisibilizou e silenciou a presença e a história de povos e culturas afrobrasileiras e indígenas no Brasil.

As análises apresentadas nos resultados e discussão, nos provocam a inferir que o processo de respeito a diversidade e inclusão não se restringe ao texto legal, mas tem rebatimento nas práticas curriculares dos cotidianos escolares e são estas que dão materialidade às lutas pela decolonialidade. As políticas e práticas curriculares carregam elementos que questionam fundamentos do padrão hegemônico de poder. Todavia, essas políticas encontram barreiras/limites impostos à sua real materialização, tais como: a falta de formação para o(a)s professore(a)s trabalhar com esta temática e, por sua vez, conhecimentos das referências que subsidiam as práticas curriculares, muitas vezes marcadas pela colonialidade.

Neste sentido, podemos afirmar que a efetivação das políticas públicas antirracistas requer um entrecruzamento de conhecimentos específicos e atitudes para superar os discursos alienantes que criou o outro para subalternizá-lo - um dos entraves para que este processo seja de fato bem sucedido. Desse modo, sob o peso das subjetividades (sentidos e significados que vem sendo construídos ao longo da vida dos seres humanos) entrelaça o sujeito ao discurso social e influencia diretamente na materialização dos processos de inclusão em sala de aula.

Portanto, diante do panorama delineado, para sanar essa carência na formação docente, as universidades têm um importante papel - o qual, segundo as Diretrizes Curriculares Nacionais para a Educação das Relações Étnico-Raciais e para o Ensino de História e Cultura Afro-Brasileira e Africana (BRASIL, 2004, p. 8) - é investir para que os professores, além de sólida formação na área específica de atuação, recebam formação que os capacite não só a compreender a importância das questões relacionadas à diversidade étnico-racial, mas a lidar positivamente com elas e, sobretudo criar estratégias pedagógicas que possam auxiliar a reeducá-las.

Ademais, as universidades cabem também, construir programas de formação continuada que possibilitem aos professores perceber os mecanismos racistas da sociedade e do material didático que excluem e estereotipam os sujeitos das escolas tidos como diferentes. Por fim, repensar os processos de formação de professores, seja ela inicial ou continuada, é tarefa urgente. 
Referências

BRASIL. Constituição da República Federativa do Brasil. Brasília, DF: Senado Federal, 1988.

BRASIL. Lei 10.639 de 9 de janeiro de 2003. Altera a Lei no 9.394, de 20 de dezembro de 1996, que estabelece as diretrizes e bases da educação nacional para incluir no currículo oficial da Rede de Ensino a obrigatoriedade da temática "História e Cultura Afro-Brasileira", e dá outras providências. Brasília, 2003.

BRASIL. Indagações Sobre Currículo: diversidade e currículo. Brasília: Ministério da Educação/Secretaria de Educação Básica, 2007.

BRASIL. Diretrizes Curriculares Nacionais para a Educação das relações étnico-raciais e para o ensino da História afro-brasileira e africana. Brasília/DF: SECAD/ME, 2004.

BRASIL. Orientações e ações para educação as relações étnico-raciais. Brasília, DF: SECAD, 2006.

BRASIL. Lei 11.645/08 de 10 de março de 2008. Altera a Lei no 10.639, de 9 de janeiro de 2003, que estabelece a inclusão no currículo da Rede de ensino a obrigatoriedade da temática "História e Cultura Afro-Brasileira" para incluir a história e cultura dos povos indígenas. Diário Oficial da União, Poder Executivo, Brasília, 2008.

BRASIL. Plano Nacional de Implementação das Diretrizes Curriculares Nacionais para a Educação das Relações Étnico-raciais e para o Ensino de História e Cultura Afro-brasileira e Africana. Brasília: SECAD; SEPPIR, jun. 2009.

BRASIL. Diretrizes Curriculares Nacionais para a Educação Escolar Indígena na Educação Básica. Brasília, DF: MEC, 2012.

BRASIL. Diretrizes Curriculares Nacionais para a Educação. Quilombola. Brasília, DF: MEC/SECADI, 2012.

BRASIL. Diretrizes Curriculares Nacionais para a Educação em Direitos Humanos. Brasília, DF: MEC, 2012.

CORENZA, Janaína de Azevedo. Formação Inicial de Professores: conversas sobre relações raciais e educação. Curitiba: Appris, 2018.

GEERTZ, Clifford. A Interpretação das Culturas. Rio de Janeiro: LTC, 2008.

GIL, Antônio Carlos. Métodos e Técnicas de Pesquisa Social. $4^{\circ}$ ed. São Paulo: Editora Atlas S.A., 1995.

LAKATOS, E. M.; MARCONI, M. A. Metodologia do trabalho científico. 4.ed. São Paulo: Atlas, 2009.

LÜDKE, Menga; ANDRÉ, Marli. Pesquisa em educação: abordagens qualitativas. São Paulo: EPU, 1986.

OLIVEIRA, Luiz Fernandes de. Concepções docentes sobre as relações étnico-raciais em educação e a lei 10.639. In: $30^{\circ}$ Reunião anual da ANPED, 2007, Caxambu. $30^{\circ}$ Reunião anual da ANPED: ANPEd: 30 
$\begin{array}{llllllll}\text { ANOS } & \text { DE } & \text { PESQUISA } & \text { E } & \text { COMPROMISSO } & \text { SOCIAL, 2007. } & \text { Disponível } & \text { em }\end{array}$ http://www.anped.org.br/reunioes/30ra/trabalhos/GT04-3068--Int.pdf > Acesso 17/08/2021

SANTOS, B. de S. A gramática do tempo. São Paulo: Cortez, 2006.

SELLTIZ, C.; WRIGHTSMAN, L. S.; COOK, S. W. Métodos de pesquisa das relações sociais. São Paulo: Herder, 1965.

TRIVIÑOS, Augusto N. S. Introdução à pesquisa em ciências sociais: a pesquisa qualitativa em educação. São Paulo: Atlas, 1987.

VYGOTSKI L.S. A formação social da mente. São Paulo: Martins Fontes, 1991. 